\title{
A Review of Embedding Artificial Intelligence in Internet of Things and Building Information Modelling for Healthcare Facility Maintenance Management
}

\author{
Mina Sadat Orooje ${ }^{1} \&$ Mohammad Mehdi Latifi $^{2}$ \\ ${ }^{1}$ Department of Architecture, Built Environment and Construction Engineering, Polytechnic University of Milan, \\ Milan, Italy \\ ${ }^{2}$ School of Management, University of Tehran, Tehran, Iran \\ Correspondence: Mina Sadat Orooje, Department of Architecture, Built Environment and Construction \\ Engineering, Polytechnic University of Milan, Milan, Italy.
}

Received: August 13, 2021

Accepted: August 28, 2021

Online Published: September 6, 2021

doi:10.5539/eer.v11n2p31

URL: https://doi.org/10.5539/eer.v11n2p31

\begin{abstract}
Latest innovations in Internet of Things (IoT) technologies as well as the new paradigms in Artificial Intelligence systems are opening up opportunities to create smart computing infrastructures for the Healthcare Facility Management. However, the current scenario of hospital buildings maintenance management is strongly characterized by slow, redundant, and not integrated processes, which lead to loss of money, resources, and time. On the other hand, lack of data and information in as-built digital models considerably limits the potential of Building Information Modelling in Facility Maintenance Management. Consequently, optimization of data collection process and management is required. In this light, this paper presents a review of embedding AI (Artificial Intelligence) in BIM-IoT integration for the process of healthcare Facility Maintenance Management (FMM) in order to conquer the current challenges. The first challenge in front of integrating IoT-BIM, is the lack of information; the second challenge is BIM's sematic information that has not been able to display indoor conditions' elements which should be reconsidered; and the third challenge is the data size which is stored in systems as well as the eligibility of individuals to apply the related data. Additionally, some emerging trends in IoT are reviewed such as the combination of Machine Learning and Artificial Intelligence in order to exploit their advantages and complement their limitations, which enable new promising IoT applications.
\end{abstract}

Keywords: Building Information Modelling (BIM), Internet of Things (IoT), Artificial Intelligence (AI), Healthcare Facility Maintenance Management; Construction 4.0

\section{Introduction}

Within the last three decades, continuous waves of technological advancements have presented a new industrial revolution in the construction sector, a so-called Industry 4.0. Compared to other sectors, the construction sector has been markedly slower to digital conversion levels and as a result, Internet of Things (IoT) and Building Information Modelling (BIM) can play significant roles in shaping the so-called revolution (Hossain \& Nadeem, 2019). This paper presents an integrated approach to embed AI in IoT applications and Building Information Modelling for Healthcare Facility Maintenance Management in hospitals buildings, and is organized as follows: (a) an overview on Healthcare Facility Maintenance Management and the impact of digitalization and innovative technologies; (b) a definition of research scope and process; (c) a comprehensive content analysis of scientific databases on AI, IoT and BIM with an integrative approach in healthcare facility maintenance management (HFMM); (d) discussion and conclusion. As the cost digital technologies in a facility management represent more than $80 \%$ of a building's total costs, many studies have investigated the utilization of digital technologies which address digital transformation in the facility management (Cheng, Chen, Chen, \& Li, 2019; Munteanu \& Mehedintu, 2016). However, compared to different phases of the construction such as initiation, planning, implementation and design, there is a huge gap of research on utilizing novel technologies in maintenance, monitoring, operation, as well as the closing stages of a building life cycle (Wong, Ge, \& He, 2018). Consequently, there are large chances for further studies on digital transformation technologies such as the integration of FM to some services and technologies like IoT, BIM, and Information Systems. IoT applications in the maintenance 
management allow to describe some new strategies including predictive maintenance, condition-based maintenance, cost management, waste reduction, and downtimes restriction (Atta, \& Talamo, 2020). However, integration of BIM-IoT is quite in its early phases and demands more endeavors to carry out a better apprehension of the present condition (Tang, Shelden, Eastman, Pishdad-Bozorgi, \& Gao, 2019). Main purposes of this paper, therefore, are to review and identify common emerging areas to embed Artificial Intelligence in Building Information Modeling (BIM), analyze how real-time data from IoT devices can improve healthcare facility maintenance management, and cover the existing gaps while outlining future research directions.

\section{Aim of the Research}

While many scholars have interactively described various features of BIM, AI, IoT and their applications, Artificial Intelligence and the integration of BIM-IoT still need more research as well as serious efforts to understand of the current situation better. Applying the collected data from IoT sensors and Artificial Intelligence devices, this paper aims to address the integration between BIM-IoT and FMM to provide a literature analysis on embedding Artificial Intelligence in BIM-IoT for healthcare facility maintenance management improvements, and define future research directions on HCFMM improvements by applying Artificial Intelligence in new technologies.

\subsection{Research Process}

As the primary objective of this research is to analyze and categorize the existing studies on AI, BIM and IoT integration for healthcare facility maintenance management, Figure 1 shows an overview of the research process.

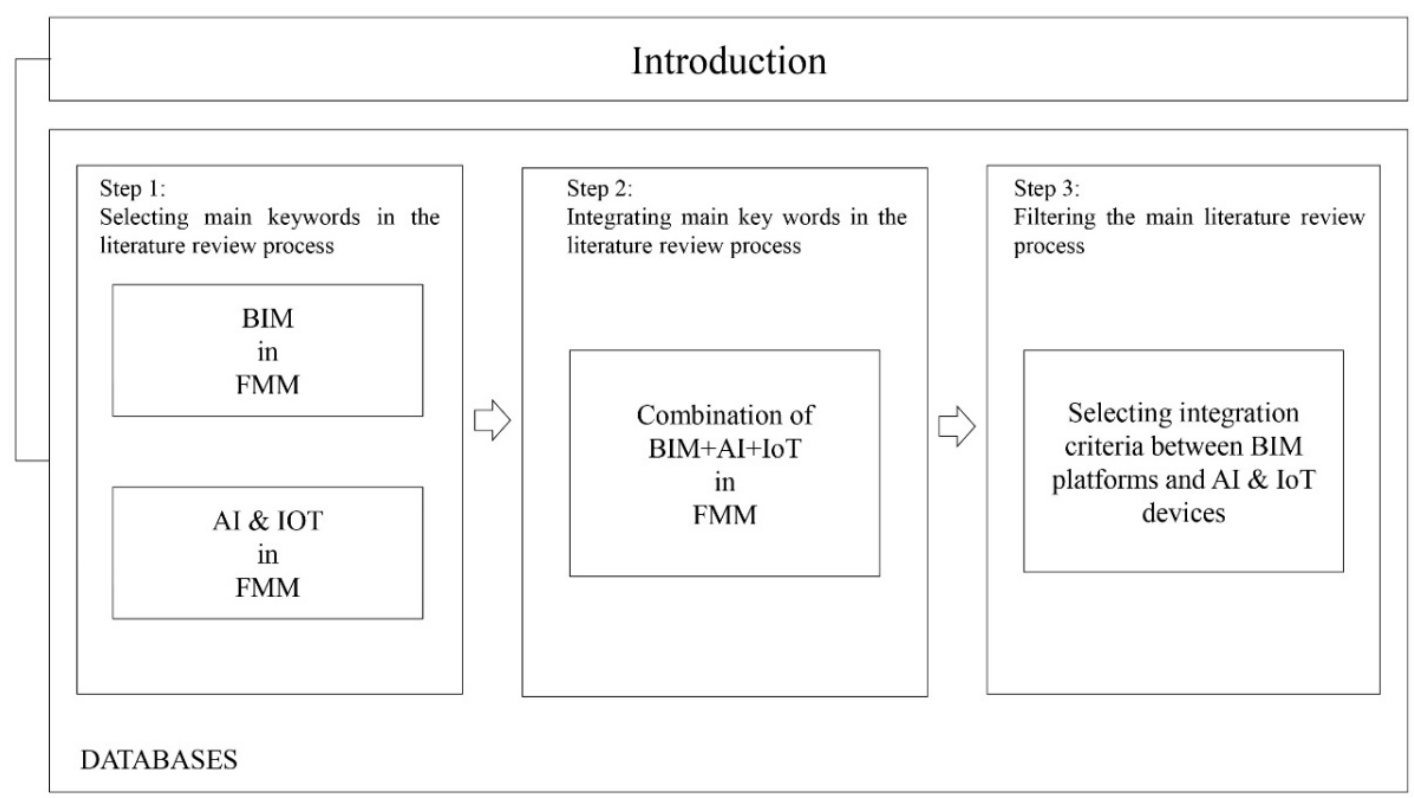

Figure 1. The Research Process

This process provides an overview on how the present research is conducted. In order to review the integration of BIM-IoT in the Facility Maintenance Management context comprehensively and identify how Artificial Intelligence is applied in BIM-IoT, two databases have been put together, namely, Science Direct and ASCE Library. The Google Scholar search engine has also been utilized to ensure accessing to a wide range of potential articles. Subsequently, the three main highly effective journals which serve as primary sources of the majority of reviewed articles include: Automation in Construction, Advanced Engineering Informatics, and Journal of Construction Engineering and Management. Also, in order to gain from the available knowledge in electronics engineering databases on Artificial Intelligence and IoT developments, IEEE Xplore database was also taken into consideration. The objective of the literature analysis presented in this research is to evaluate the existing research findings, analyze academic publications, and trends, and identify the related directions. First, the research keywords are categorized into two main groups, each related to one of the main concepts of the study. As the second step, the terms within the first group which are related to the concept of FM are extracted: "Building Information Modeling or BIM", and "BIM tools". The terms within the second group which are related to the concept of FMM include: "IoT or Internet of Things", "AI or Artificial Intelligence", "Cyber-Physical Systems" (Terreno, Akanmu, Anumba, \& Olayiwola, 2020), "Sensors", "Sensing Devices" (Baek, Ha, \& Kim, 2019), and "Remote Sensing" (Estes, Sailer, \& Tinney, 1986), As the third step, different combinations of keywords from both previous steps were applied to find articles relevant to Artificial Intelligence and BIM-IoT in the FMM process. 
The mentioned steps are illustrated as Table 1.

Table 1. Three Steps of the Research Process

\begin{tabular}{ccl}
\hline Groups & Steps & \multicolumn{1}{c}{ Keywords } \\
\hline BIM & Step 1 & $\begin{array}{l}\text { "Building Information Modelling or BIM" and "BIM tools". } \\
\text { AI Tols such as "Cyber-Physical Systems", "Sensors", "Wireless Sensor }\end{array}$ \\
AI \& IoT & Step 2 & $\begin{array}{l}\text { Networks", "WSN", "Sensing devices", "Remote sensing", and "Internet of } \\
\text { Things or IoT", }\end{array}$ \\
BIM + AI \& IoT & Step 3 & $\begin{array}{l}\text { Different combinations of keywords from both previous steps were applied to find } \\
\text { articles relevant to Artificial Intelligence and BIM-IoT in the FMM process. }\end{array}$
\end{tabular}

Finally, in order to acquire higher quality documents, some selection criteria were applied in order to refine the following concepts: "Facility Maintenance Management", “Operation and Maintenance”, "Healthcare Facility Management", "Big Data", and "Real Time Data in facility Management". These activities led to clarify a seamless integration between BIM platforms and AI-IoT devices.

\section{Literature Review}

\subsection{Healthcare Facility Maintenance Management}

Currently, facility management is defined as "a desegregate method to support, improve, and adapt the facilities within a building in order to create an environment which strongly supports the primary objectives of an organization" (Barrett, 2000). Therefore, facility management can be considered as an integrative topic that involves collaboration and coordination of different individuals (Chung, Kwon, Moon, \& Ko, 2018). The rising complication of healthcare facilities is mostly as a result of increasing urbanization, as well as the advancement of technologies in improving medical equipment and contents. Nowadays, hospitals must prepare various services such as healthcare to the patients. The increasing number of healthcare facilities in hospitals which provide essential services 24 hours a day, 7 days a week, is consistently greater than any other buildings (Yousefli, Nasiri, \& Moselhi, 2017). Shohet et al. (2004) recognize five core sections (the "pentagon") in healthcare facility management: maintenance management, performance management, risk management, supply services management, and development. Information and Communications Technologies (ICT) is addressed as an integrator among all of these five sections (Shohet, \& Lavy, 2004). Recently, it was intended to improve maintenance management operations in hospitals, mostly via implementing maintenance policies, performance calculations, and IT applications in order to optimize costs, plans, and productivity of hospitals (Gómez-Chaparro, García-Sanz-Calcedo, \& Aunión-Villa, 2020; Amos, Musa, \& Au-Yong, 2020). Currently, as a result of misused procedures, absence of data, and lack of reliable information systems, hospital buildings lack an optimal management (Mannino, Dejaco, \& Re Cecconi, 2021). For instance, data which are delivered by FM information systems such as Computerized Maintenance Management Systems (CMMS), and Building Automation Systems (BAS), are often disintegrated and incomplete. This scarcity and disintegration could generate difficult and inefficient processes (Wong, Ge, \& He, 2018). According to Yousefli et al. (2017) and Alzaben (2015), these difficult and inefficient processes include deferred maintenance of semipublic hospitals. In order to solve the problems related to the maintenance issues, both the maintenance functionality and resource administration processes must be improved (Alzaben, 2015; Yousefli, Nasiri, \& Moselhi, 2017). In hospital buildings, facility managers are overwhelmed by huge amounts of data with ongoing needs for frequent renovations. Lucas et al. (2013) state that due to the lack of well documented information on maintenance activities in complex buildings (hospitals, for instance), making significant mistakes by facility managers are very common (Lucas, Bulbul, Thabet, \& Anumba, 2013). The complexity of healthcare facility management is characterized by different sorts of data, including both quantitative data (e.g. maintenance resources, physical performance, and energy consumption), and data that need to be quantified to be implemented in FM (e.g. types of facilities, and maintenance policies) (Mannino, Dejaco, \& Re Cecconi, 2021). The complexity of healthcare facility management is characterized by the existence of different sorts of data in maintenance resources, physical performance, and energy consumption, as well as the data which require a means of quantification to be implemented in FM. On the other hand, most of data in healthcare facilities are partially missing or incomplete (Lucas, Bulbul, \& Thabet, 2013).

\subsection{Digital Transformation in Facility Management}

Digital technologies have changed everybody's daily activities and have revolutionized many regular practices which aim to obtain precision, productivity, and efficiency (Mannino, Dejaco, \& Re Cecconi, 2021). This 
revolution in digital transformation has revealed new developments in different generations of FM sector while there is a clear lack of tools and references. Lucas et al. (2013) and Konanahalli et al. (2018) state that because of the advancements in technologies such as big data, IoT, cloud computing, and cyber-physical systems, these developments have gained momentum. Besides, the strengths of these advancements lie in interoperability, controlling, monitoring, real-time information processing, and self-optimization processing (Lucas, Bulbul, \& Thabet, 2013; Konanahalli, Oyedele, Marinelli, \& Selim, 2018). Indeed, when discussing about digitalization revolution, it is essential to acknowledge that it is not only a technological change in the operational level; but also, it involves the creation of new probabilities for a widespread monitoring of appropriate parameters (Talamo, Atta, Martani, \& Paganin, 2016). Ashworth et al. (2019) state that the main effort of digital transformation in the construction sector is to increase the sector's efficiency, which will be achieved by the spread of BIM (Ashworth, Tucker, \& Druhmann, 2019). New market demands require companies to be flexible and innovative, while forcing them to relocate from the traditional culture to novel strategies aimed at forecasting future directions (Konanahalli, Oyedele, Marinelli, \& Selim, 2018).

\subsection{Building Information Modelling in FM}

$\mathrm{Xu}$ et al. (2021) define BIM as "a process of creating and managing consistent building data that ease the achievement of established sustainability objectives". During recent years, BIM has been more and more applied in the architecture, engineering, and construction (AEC) industries (Xu, Mumford, \& Zou, 2021). Applying BIM Models, building administrators will be able to manage information all around the building, accordingly enhancing different phases of FM. BIM usage for healthcare facilities has many benefits such as good visualization, saving time, and quantity takeoffs which should be explored in early programming periods (Manning, \& Messner, 2008). However, in order to apply BIM in healthcare FM successfully, several issues must be addressed. For instance, some equipment types such as elevator systems, fire alarm systems, heating systems, ventilation systems, and air conditioning (HVAC) systems, are controlled by different contractors, and therefore, the FM workforce should monitor each proprietary system individually to locate the needed information. Huge amount of data which belong to different stages of the project should be utilized by separate parties at various levels of detail and should be stored in different formats such as engineering drawings, handwritten papers, and even oral presentations. Furthermore, FM procedures need some guidelines or standards. Lucas et al. (2013) analyzed large scale of healthcare standards and guidelines and concluded that they can be integrated into a healthcare facility information framework to encourage facility operations and maintenance performance compliances. By developing a 3D model during the design and construction phases, BIM works more efficiently and enables project time and cost calculation. Besides, it provides data throughout the stages of the building life cycle in order to apply them in maintenance activities and operations management (Lucas, Bulbul, \& Anumba, 2013). Advantages of applying BIM in FM is that facility managers will be able to work on information while applying one data source, preparing "as-is" information, and solving all of the problems derived from the sources' disintegration (Wang, Bulbul, \& Lucas, 2015). Each BIM model is consisted of various Levels of Development-LoD (Mannino, Dejaco, \& Re Cecconi, 2021) that specifies how much data is involved in setting up a part. If LoD is higher, the reliability and clarity of data and information will be greater. BIM fully considers the environmental issues regarding the ever growing demands for renovating and new buildings particularly in a superior indoor environment that has influenced the construction and designing of the building. Moreover, by maintaining the old buildings in an upright shape and making them suitable for living, BIM could fully cover the old buildings (Ansah, Chen, Yang, Lu, \& Lam, 2019). Although applying BIM has several advantages, it is not often integrated in all aspects of FM phases. The most important reason is that it provides static information. In other words, data are available throughout design stages but will not be renovated through the building's life cycle (Patacas, Dawood, Vukovic, \& Kassem, 2015), Furthermore, Wong et al (2018) state that another reason for this phenomenon is an absence of engagement of facility managers in creating BIM models (Wong, Ge, \& He, 2018).

\subsection{Internet of Things (IoT) in FM}

According to Patel et al. (2016), "IoT is a system of physical items. Internet can be considered as a network of devices and entities such as smart phones, toys, medical instruments, animals, buildings, individuals all connected." Gubbi et al. (2013) state that IoT has resulted in a linkage between objects and people at an extraordinary pace and scale which will make new strategies to improve quality of life (Gubbi, Buyya, Marusic, \& Palaniswami, 2013; Pradeep, Kousalya, Suresh, \& Edwin, 2016). Therefore, IoT can become a network of connected devices that have communication functions (Lee, H. J., \& Kim, M. (2018). In the IoT-based FM vision, sensors and IoT devices play a pivotal role while it is becoming one of the fundamental technologies of digital transformation in the FM sector at full tilt. IoT is able to merge virtual and physical worlds and make them communicate throughout an intelligent digital interface because it is capable of connecting building components, users, and services. Maintenance and 
operation stages of IoT constitutes $50 \%$ to $70 \%$ of the annual facility operating expenditures (Rondeau, Brown, \& Lapides, 2012). The building management requires to integrate and analyze various types of information and data which are created by different stakeholders. IoT as well as smart connections are capable of optimizing both the building performance and FM activities. Thanks to real-time sensor data, IoT can increase the potentials of facility managers to produce and update knowledge bases, keep them in a cloud, and process data all over the intelligent systems as the information platforms (Atta, \& Talamo, 2020). According to Cirillo et al, (2019) and Al-Sarawi et al. (2020), the overall IoT Market in the world will reach $\$ 1,567$ bn by 2025 and there will be 75.44 billion devices which are connected to the internet worldwide by 2025 (Cirillo, Solmaz, Berz, Bauer, Cheng, \& Kovacs, 2019; Al-Sarawi, Anbar, Abdullah, \& Al Hawari, 2020). Therefore, IoT and intelligence sensors are applied to designate virtual identities to objects through assigning them a variety of features (e.g. appropriate parameters of interest including motion, position, etc.) in the format of big data (Konanahalli, Oyedele, Marinelli, \& Selim, 2018).

\subsection{Artificial Intelligence in FM}

First, a definition of Artificial Intelligence (AI) can be about either the usage of a word or the content of a concept expressed by a word, and in most situations the debate on the meaning of AI is more about the latter than about the former, though it is the former that is directly mentioned. In the current discussion, if "Artificial Intelligence" was replaced by "computer intelligence" or "machine intelligence," then the underlying problem would not change much. AI, however, can be defined as "the study of techniques to solve significantly difficult problems by making use of knowledge regarding a problem domain" (Wang, 2019). Because it has gained several developments recently, AI plays a very crucial role in various fields including planning and problem-solving systems, open language processing systems, expert systems, computer vision systems, robotics, machine learning, neural networks, and genetic algorithms (Krishnamoorthy, \& Rajeev, 1996). The easy and quick access to data and information help facility managers both avoid making mistakes in decisions and minimize the required personnel and time in recovering information (Ergen, Akinci, \& Sacks, 2007). Hu et al. (2016) state that maintenance and operation engineering may include different subsystems and each system is consisted of many complicated parts. Although each subsystem grows, facility workforce cannot classify the maintenance and operation (M\&O) asset (Hu, Zhang, Yu, Tian, \& Xiang, 2016). Teicholz (2004) states that maintenance allocation and operation expenditures in FMM could reach to $60 \%$ of the entire expenditures (Teicholz, 2004). If facility managers depend on that there is no regular or scheduled maintenance, then the majority of the maintenance will be responsive that may cause sudden collapse in operations and as a result the life cycle cost (LCC) will be increased (Lavy, 2008). Mostly, each facility may be consisted of same maintenance and operation elements, but with different components, equipment, and materials which are necessary for both reactive and proactive maintenances. The facility's component localization is labor-consuming, time-consuming, and a monotonous job to FM staff particularly for the outsourced ones (Becerik-Gerber, Jazizadeh, Li, \& Calis, 2012). As a conclusion, Marzouk et al. (2020) state that Artificial Intelligence in FM increases the ability of facility managers to oversee and recall details affecting day-to-day operations. Using self-optimizing systems powered by the Internet of Things (IoT), Artificial Intelligence in FM can eliminate uncertainty and let computers do the thinking, while freeing up time for facility managers (Marzouk, \& Zaher, 2020).

\section{Results}

As mentioned before, many reviewed papers have focused on IoT and Artificial Intelligence, only few papers presented BIM. Although integrating BIM to AIoT is quite at its prior stage (Bilal, Oyedele, Qadir, Munir, Ajayi, Akinade, ... Pasha, 2016), a large bunch of research throughout the recent years show that BIM-IoT integration is a novel area of interest through 2019 to 2020 (Mannino, Dejaco, M \& Re Cecconi, 2021). Accordingly, the implementation of BIM-IoT integration for FM can be considered as a novel domain. As illustrated in Table 2, most of the research on Artificial Intelligence and BIM-IoT integration for FMM have been published in the journal of "Automation in Construction". The literature analysis of articles has also revealed that BIM is largely applied and developed in South Korea, USA, and China (Zhao, 2017). 
Table 2. The Most Cited Articles on AI, BIM, and IoT (Until May 2021)

\begin{tabular}{|c|c|c|c|c|}
\hline No. & Authors & Title & Citation & Source \\
\hline 1 & $\begin{array}{l}\text { Wang, X.; Love, P.E.D.; } \\
\text { Kim, Mi Jeong et al. (2013) }\end{array}$ & $\begin{array}{c}\text { A conceptual framework for } \\
\text { integrating building information } \\
\text { modeling with augmented reality. } \\
\text { (IT) }\end{array}$ & 216 & $\begin{array}{l}\text { Automation in } \\
\text { Construction }\end{array}$ \\
\hline 2 & $\begin{array}{l}\text { Tang, S., Shelden, D.R., } \\
\text { Eastman, C.M., Pishdad- } \\
\text { Bozorgi, P., Gao, X (2019) }\end{array}$ & $\begin{array}{l}\text { A review of building information } \\
\text { modeling (BIM) and the internet of } \\
\text { things (IoT) devices integration: } \\
\text { Present status and future trends }\end{array}$ & 168 & $\begin{array}{l}\text { Automation in } \\
\text { Construction }\end{array}$ \\
\hline 3 & $\begin{array}{l}\text { Marzouk, M., \& Abdelaty, } \\
\text { A. (2014). }\end{array}$ & $\begin{array}{l}\text { Monitoring thermal comfort in } \\
\text { subways using building information } \\
\text { modeling }\end{array}$ & 158 & $\begin{array}{l}\text { Automation in } \\
\text { Construction }\end{array}$ \\
\hline 4 & $\begin{array}{l}\text { Zhong, R.Y., Peng, Y., Xue, } \\
\text { F. et al. (2017) }\end{array}$ & $\begin{array}{l}\text { Prefabricated construction enabled by } \\
\text { the Internet of Things. (PM) }\end{array}$ & 149 & $\begin{array}{l}\text { Automation in } \\
\text { Construction }\end{array}$ \\
\hline 5 & $\begin{array}{l}\text { Park, J., Kim, K., Cho, Y.K } \\
\text { (2017) }\end{array}$ & $\begin{array}{c}\text { Framework of Automated } \\
\text { Construction -Safety Monitoring } \\
\text { Using Cloud-Enabled BIM and BLE } \\
\text { Mobile Tracking Sensors }\end{array}$ & 143 & $\begin{array}{l}\text { Journal of } \\
\text { Construction } \\
\text { Engineering and } \\
\text { Management }\end{array}$ \\
\hline 6 & $\begin{array}{l}\text { Riaz, Z., Arslan, M., Kiani, } \\
\text { A.K., Azhar, S. (2014) }\end{array}$ & $\begin{array}{l}\text { CoSMoS: A BIM and wireless sensor } \\
\text { based integrated solution for worker } \\
\text { safety in confined spaces }\end{array}$ & 132 & $\begin{array}{l}\text { Automation in } \\
\text { Construction }\end{array}$ \\
\hline 7 & $\begin{array}{l}\text { Fang, Y., Cho, Y.K., Zhang, } \\
\text { S., Perez, E. (2016) }\end{array}$ & $\begin{array}{l}\text { Case Study of BIM and Cloud- } \\
\text { Enabled Real-Time RFID Indoor } \\
\text { Localization for Construction } \\
\text { Management Applications (PM) }\end{array}$ & 128 & $\begin{array}{l}\text { Journal of } \\
\text { Construction } \\
\text { Engineering and } \\
\text { Management }\end{array}$ \\
\hline
\end{tabular}

\section{Discussion and Conclusion}

Integrating the big data into the construction industry provides future trends and new opportunities. A huge bunch of research which have been reviewed during 2016 illustrated that Big Data has a great potentiality to be associated with the construction industry as well as the healthcare industry (Bilal, Oyedele, Qadir, Munir, Ajayi, Akinade, ... Pasha, 2016). As Maintenance and Operations (M\&O) of facilities play crucial roles in Healthcare FM, M\&O competence in FM is changing to one of the most research areas, as well as one of the preliminary study fields in integrating big data into FM (Zhao, 2017). Since 2013, BIM-sensor integration for Structural Health Monitoring (SHM) has become one of the most interesting topics and has been addressed for years (Rio, Ferreira, \& Martins, 2013). Many researchers have studied the interrelation between BIM and real-time data while they came to a conclusion that sensors data can be stored in the BIM model. Zhao (2017), whose study gained a lot of recognition, also tried to integrate big data into the construction industry and applied semantic Construction Digital Twin in the BIM (Zhao, 2017). Dave et al. (2018) created various fields which include information systems, BIM, IoT devices, and automation systems for the end-users (Dave, Buda, Nurminen, \& Främling, 2018). Valinejadshoubi et al. (2019) presented an external database and proposed an information modelling framework for SHM. Their approach supports dynamic visualization of key structural performance parameters, allowing for the seamless updating and long-term management of data which facilitates data exchange while generating models compliant with Industry Foundation Classes (IFC) (Valinejadshoubi, Bagchi, \& Moselhi, 2019). Fitz et al. (2019) introduced the concept of Cyber-Physical Systems (CPS) and presented a Meta Model to describe it (Fitz, Theiler, \& Smarsly, 2019). Hu et al. (2016) applied hybrid architecture to integrate the contextual information into time-series data (Hu, Corry, Curry, Turner, \& O'Donnell, 2016). Gimenez et al. (2016) built on the systematic application of BIM and Information and Communication Technologies (ICT) tools. Their promising conclusion revealed that such solutions can form the core parts of future digital technologies required for renovation designs (Gimenez, Robert, Suard, \& Zreik, 2016). Cheng et al. (2020) have studied a data-driven predictive maintenance framework which were rested on IoT, machine learning algorithms and BIM. They stated that the framework of a data-driven predictive maintenance planning which is rested on technologies of IoT- BIM for FMM which are consisted of application and information layers should be developed in order to provide a better maintenance strategy for building facilities (Cheng, Chen, Chen, \& Wang, 2020). A research performed by Koh (2020) proposed an effective sensing data and HVAC for subsystems such as securities, lightings, and sensors. The research provides metadata 
models as well as guidelines for novel devices including a thermostat called Genie, and energy dashboards to build portable applications for smart buildings (Koh, 2020). Marzouk et al. (2020) aimed to classify and localize Mechanical, Electrical, and Plumbing (MEP) elements to help facility managers do their responsibilities effectively and decrease the technical complexity and sophistication of different subsystems. Authors attempted to exploit Artificial Intelligence (AI) in FM operations through proposing a new system that uses a deep learning pre-trained model for transfer learning. Their research sheds light on the maintenance of MEP elements that eventually lead to lower life cycle costs. These MEP elements have a big share in the operation and maintenance costs of building facilities (Marzouk, \& Zaher, 2020). González García et al. (2019) describe Artificial Intelligence and some of its branches such as Machine Learning, Computer Vision, Fuzzy Logic, and Natural Language Processing, while relating them to the Internet of Things. They proposed algorithms to process different information or techniques used to create appropriate models of smarter machines or programs which use the Internet of Things, better modules with enough intelligence to automate and make good decisions, a Computer Vision to automate visual scenarios, a Fuzzy Logic to give intelligence and offer decisions to save money, and so on (González García, Núñez Valdéz, García Díaz, Pelayo García-Bustelo, \& Cueva Lovelle, 2019).

\section{Contribution of the Research}

The increasing implementation of IoT applications, sensors, and smart devices in different constructions such as hospitals has generated massive amounts of information, allowing operations to become more efficient and sustainable. AI is the technology that harnesses these enormous pools of information to leverage insights to best advantage. This review paper provided an overview of embedding AI in BIM and IoT in the healthcare facility management. Implementing IoT application is the first stage of AIoT and BIM is considered as a connection for real-time data implementation/IoT. Even though BIM is mostly applied in the phase of the building design, there is quite much to do for the whole buildings lifecycle and also its application in Facility Maintenance Management. However, many studies have explored the possible synergy between these two fields. The reviewed literature shows that IoT- BIM integration in operation and maintenance competence of facility management is in early stages of research. The first challenge facing the development of a new IoT- BIM integration is the absence of a BIM approach into information requirements; the second challenge is the proper information of BIM that couldn't show components of indoor conditions which should be reconsidered; and the third challenge is the size of information and data which are stored in a system as well as the eligibility of users to use the related data. Many articles mentioned the benefits of embedding $\mathrm{AI}$ in IoT devices for a reliable facility maintenance management, such as a real-time response of automated systems. The future studies should focus on challenges of visualizing and managing the acquired data not only during a single phase, but also during the whole lifecycle of a facility. BIM models which have adequate data will be crucial to fully hold up the monitoring of facilities. Further research is needed to recognize censorious locations automatically in which sensors are required, various kinds of sensors are needed to observe censorious elements, and sensors data integration in order to enhance $M \& O$ management.

\section{Acknowledgements}

This project would not have been possible without the support of Dr. Ali Rashidi, Monash University, who read my numerous revisions, helped make the sense of motivation, and offered guidance and support. And thanks to my parents and numerous friends who endured this long process with me, always offering support and love.

\section{References}

Al-Sarawi, S., Anbar, M., Abdullah, R., \& Al Hawari, A. B. (2020, July). Internet of Things Market Analysis Forecasts, 2020-2030. In 2020 Fourth World Conference on Smart Trends in Systems, Security and Sustainability (WorldS4) (pp. 449-453). IEEE. https://doi.org/10.1109/worlds450073.2020.9210375

Alzaben, H. (2015). Development of a maintenance management framework to facilitate the delivery of healthcare provisions in the Kingdom of Saudia Arabia (Doctoral dissertation, Nottingham Trent University).

Amos, D., Musa, Z. N., \& Au-Yong, C. P. (2020). Performance measurement of facilities management services in Ghana's public hospitals. Building Research \& Information, 48(2), 218-238. https://doi.org/10.1080/09613218.2019.1660607

Ansah, M. K., Chen, X., Yang, H., Lu, L., \& Lam, P. T. (2019). A review and outlook for integrated BIM application in green building assessment. Sustainable Cities and Society, 48, 101576. https://doi.org/10.1016/j.scs.2019.101576

Ashworth, S., Tucker, M., \& Druhmann, C. K. (2019). Critical success factors for facility management employer's information requirements (EIR) for BIM. Facilities. https://doi.org/10.1108/f-02-2018-0027

Atta, N., \& Talamo, C. (2020). Digital Transformation in Facility Management (FM). IoT and Big Data for Service 
Innovation in Digital Transformation of the Design. Construction and Management Processes of the Built Environment (pp. 267-278). Springer, Cham. https://doi.org/10.1007/978-3-030-33570-0_24

Barrett, P. (2000). Achieving strategic facilities management through strong relationships. Facilities. https://doi.org/10.1108/02632770010349655

Baek, F., Ha, I., \& Kim, H. (2019). Augmented reality system for facility management using image-based indoor localization. Automation in Construction, 99, 18-26. https://doi.org/10.1016/j.autcon.2018.11.034

Becerik-Gerber, B., Jazizadeh, F., Li, N., \& Calis, G. (2012). Application areas and data requirements for BIMenabled facilities management. Journal of construction engineering and management, 138(3), 431-442. https://doi.org/10.1061/(asce)co.1943-7862.0000433

Bilal, M., Oyedele, L. O., Qadir, J., Munir, K., Ajayi, S. O., Akinade, O. O., ... Pasha, M. (2016). Big Data in the construction industry: A review of present status, opportunities, and Cheng, J.C.P nds. Advanced engineering informatics, 30(3), 500-521. https://doi.org/10.1016/j.aei.2016.07.001

Chen, K., Chen, W., Li, C. T., \& Cheng, J. C. (2019). A BIM-based location aware AR collaborative framework for facility maintenance management. J. Inf. Technol. Constr., 24, 360-380. https://doi.org/10.1061/9780784481295.012

Cheng, J. C., Chen, W., Chen, K., \& Wang, Q. (2020). Data-driven predictive maintenance planning framework for MEP components based on BIM and IoT using machine learning algorithms. Automation in Construction, 112, 103087. https://doi.org/10.1016/j.autcon.2020.103087

Chung, S., Kwon, S., Moon, D., \& Ko, T. (2018). Smart Facility Management Systems Utilizing Open BIM and Augmented. In Virtual Reality. In 35th International Symposium on Automation and Robotics in Construction. https://doi.org/10.22260/isarc2018/0118

Cirillo, F., Solmaz, G., Berz, E. L., Bauer, M., Cheng, B., \& Kovacs, E. (2019). A standard-based open source IoT platform: FIWARE. IEEE Internet of Things Magazine, 2(3), 12-18. https://doi.org/10.1109/iotm.0001.1800022

Dave, B., Buda, A., Nurminen, A., \& Främling, K. (2018). A framework for integrating BIM and IoT through open standards. Automation in Construction, 95, 35-45. https://doi.org/10.1016/j.autcon.2018.07.022

Ergen, E., Akinci, B., \& Sacks, R. (2007). Life-cycle data management of engineered-to-order components using radio frequency identification. Advanced Engineering Informatics, 21(4), 356-366. https://doi.org/10.1016/j.aei.2006.09.004

Estes, J. E., Sailer, C., \& Tinney, L. R. (1986). Applications of Artificial Intelligence techniques to remote sensing. The Professional Geographer, 38(2), 133-141. https://doi.org/10.1111/j.0033-0124.1986.00133.x

Fang, Y., Cho, Y. K., Zhang, S., \& Perez, E. (2016). Case study of BIM and cloud-enabled real-time RFID indoor localization for construction management applications. Journal of Construction Engineering and Management, 142(7), 05016003. https://doi.org/10.1061/(asce)co.1943-7862.0001125

Fitz, T., Theiler, M., \& Smarsly, K. (2019). A metamodel for cyber-physical systems. Advanced engineering informatics, 41, 100930. https://doi.org/10.1016/j.aei.2019.100930

Gimenez, L., Robert, S., Suard, F., \& Zreik, K. (2016). Automatic reconstruction of 3D building models from scanned 2D floor plans. Automation in Construction, 63, 48-56. https://doi.org/10.1016/j.autcon.2015.12.008

Gómez-Chaparro, M., García-Sanz-Calcedo, J., \& Aunión-Villa, J. (2020). Maintenance in hospitals with less than 200 beds: efficiency indicators. Building Research \& Information, 48(5), 526-537. https://doi.org/10.1080/09613218.2019.1678007

González García, C., Núñez Valdéz, E. R., García Díaz, V., Pelayo García-Bustelo, B. C., \& Cueva Lovelle, J. M. (2019). A review of Artificial Intelligence in the internet of things. International Journal Of Interactive Multimedia And Artificial Intelligence, 5. https://doi.org/10.9781/ijimai.2018.03.004

Gubbi, J., Buyya, R., Marusic, S., \& Palaniswami, M. (2013). Internet of Things (IoT): A vision, architectural elements, and future directions. Future generation computer systems, 29(7), 1645-1660. https://doi.org/10.1016/j.future.2013.01.010

Hossain, A., \& Nadeem, A. (2019). Towards digitizing the construction industry: State of the art of construction 4.0. Structural Engineering and Construction Management, 1-6. https://doi.org/10.14455/isec.res.2019.184

Hu, S., Corry, E., Curry, E., Turner, W. J., \& O'Donnell, J. (2016). Building performance optimisation: A hybrid 
architecture for the integration of contextual information and time-series data. Automation in Construction, 70, 51-61. https://doi.org/10.1016/j.autcon.2016.05.018

Hu, Z. Z., Zhang, J. P., Yu, F. Q., Tian, P. L., \& Xiang, X. S. (2016). Construction and facility management of large MEP projects using a multi-Scale building information model. Advances in Engineering Software, 100, 215 230. https://doi.org/10.1016/j.advengsoft.2016.07.006

Koh, J. B. (2020). Metadata Models and Methods for Smart Buildings (Doctoral dissertation, UC San Diego)

Konanahalli, A., Oyedele, L., Marinelli, M., \& Selim, G. (2018). Big data: a new revolution in the UK facilities management sector. https://doi.org/10.1109/tem.2019.2959914

Krishnamoorthy, C. S., \& Rajeev, S. (1996). Artificial Intelligence and expert systems for engineers, 11. CRC press. https://doi.org/10.1016/s0957-4174(97)86774-7

Lavy, S. (2008). Facility management practices in higher education buildings: A case study. Journal of Facilities Management. https://doi.org/10.1108/14725960810908163

Lee, H. J., \& Kim, M. (2018). The Internet of Things in a smart connected world. Internet of Things-Technology, Applications and Standardization, 91. https://doi.org/10.5772/intechopen.76128

Lucas, J., Bulbul, T., \& Anumba, C. (2013). Gap analysis on the ability of guidelines and standards to support the performance of healthcare facilities. Journal of performance of constructed facilities, 27(6), 748-755. https://doi.org/10.1061/(asce)cf.1943-5509.0000364

Lucas, J., Bulbul, T., \& Thabet, W. (2013). An object-oriented model to support healthcare facility information management. Automation in Construction, 31, 281-291. https://doi.org/10.1016/j.autcon.2012.12.014

Lucas, J., Bulbul, T., Thabet, W., \& Anumba, C. (2013). Case analysis to identify information links between facility management and healthcare delivery information in a hospital setting. Journal of Architectural Engineering, 19(2), 134-145. https://doi.org/10.1061/(asce)ae.1943-5568.0000111

Manning, R., \& Messner, J. I. (2008). Case studies in BIM implementation for programming of healthcare facilities. Electronic Journal of Information Technology in Construction, 13, 446-457.

Mannino, A., Dejaco, M. C., \& Re Cecconi, F. (2021). Building Information Modelling and Internet of Things Integration for Facility Management_Literature Review and Future Needs. Applied Sciences, 11(7), 3062. https://doi.org/10.3390/app11073062

Marzouk, M., \& Abdelaty, A. (2014). Monitoring thermal comfort in subways using building information modeling. Energy and Buildings, 84, 252-257. https://doi.org/10.1016/j.enbuild.2014.08.006

Marzouk, M., \& Zaher, M. (2020). Artificial Intelligence exploitation in facility management using deep learning. Construction Innovation. https://doi.org/10.1108/ci-12-2019-0138

Munteanu, A., \& Mehedintu, G. (2016). The importance of facility management in the life cycle costing calculation. Review of General Management, 23(1), 65-77.

Park, J., Kim, K., \& Cho, Y. K. (2017). Framework of automated construction-safety monitoring using cloudenabled BIM and BLE mobile tracking sensors. Journal of Construction Engineering and Management, 143(2), 05016019. https://doi.org/10.1061/(asce)co.1943-7862.0001223

Patacas, J., Dawood, N., Vukovic, V., \& Kassem, M. (2015). BIM for facilities management: evaluating BIM standards in asset register creation and service life planning. Journal of Information Technology in Construction, 20(10), 313-318. https://doi.org/10.1016/j.autcon.2020.103366

Patel, K. K., \& Patel, S. M. (2016). Internet of things-IOT: definition, characteristics, architecture, enabling technologies, application \& future challenges. International journal of engineering science and computing, 6(5). https://doi.org/10.1145/3109761.3109768

Pradeep, S., Kousalya, T., Suresh, K. A., \& Edwin, J. (2016). IoT and its connectivity challenges in smart home. International Research Journal of Engineering and Technology,3(12), 1040-1043. https://doi.org/10.1109/icbdsc.2016.7460395

Riaz, Z., Arslan, M., Kiani, A. K., \& Azhar, S. (2014). CoSMoS: A BIM and wireless sensor based integrated solution for worker safety in confined spaces. Automation in construction, 45, 96-106. https://doi.org/10.1016/j.autcon.2014.05.010

Rio, J., Ferreira, B., \& Martins, J. P. P. (2013). Expansion of IFC model with structural sensors. https://doi.org/10.3989/ic.12.043 
Rondeau, E. P., Brown, R. K., \& Lapides, P. D. (2012). Facility management. John Wiley \& Sons. https://www.wiley.com/en-it

Shohet, I. M., \& Lavy, S. (2004). Healthcare facilities management: state of the art review. Facilities. https://doi.org/10.1108/02632770410547570

Talamo, C., Atta, N., Martani, C., \& Paganin, G. (2016). The integration of physical and digital urban infrastructures: the role of "Big data". TECHNE-Journal of Technology for Architecture and Environment, 217-225. https://doi.org/10.1007/978-3-030-33570-0_24

Tang, S., Shelden, D. R., Eastman, C. M., Pishdad-Bozorgi, P., \& Gao, X. (2019). A review of building information modeling (BIM) and the internet of things (IoT) devices integration: Present status and future trends. Automation in Construction, 101, 127-139. https://doi.org/10.1016/j.autcon.2019.01.020

Teicholz, E. (2004). Bridging the AEC/FM technology gap. IFMA Facility Management Journal, 2, 1-8.

Terreno, S., Akanmu, A., Anumba, C. J., \& Olayiwola, J. (2020). Cyber-Physical Social Systems for Facility Management. In Cyber-Physical Systems in the Built Environment (pp. 297-308). Springer, Cham. https://doi.org/10.1007/978-3-030-41560-0_16

Valinejadshoubi, M., Bagchi, A., \& Moselhi, O. (2019). Development of a BIM-based data management system for structural health monitoring with application to modular buildings: Case study. Journal of Computing in Civil Engineering, 33(3), 05019003. https://doi.org/10.1061/(asce)cp.1943-5487.0000826

Wang, P. (2019). On defining Artificial Intelligence. Journal of Artificial General Intelligence, 10(2), 1-37. https://doi.org/10.2478/jagi-2019-0002

Wang, Z., Bulbul, T., \& Lucas, J. (2015). A case study of BIM-based model adaptation for healthcare facility management-information needs analysis. In Computing in Civil Engineering 2015 (pp. 395-402). https://doi.org/10.1061/9780784479247.049

Wang, X., Love, P. E., Kim, M. J., Park, C. S., Sing, C. P., \& Hou, L. (2013). A conceptual framework for integrating building information modeling with augmented reality. Automation in construction, 34, 37-44. https://doi.org/10.1016/j.autcon.2012.10.012

Wong, J. K. W., Ge, J., \& He, S. X. (2018). Digitisation in facilities management: A literature review and future research directions. Automation in Construction, 92, 312-326. https://doi.org/10.1016/j.autcon.2018.04.006

Xu, X., Mumford, T., \& Zou, P. X. (2021). Life-cycle building information modelling (BIM) engaged framework for improving building energy performance. Energy and Buildings, 231, 110496. https://doi.org/10.1016/j.enbuild.2020.110496

Yousefli, Z., Nasiri, F., \& Moselhi, O. (2017). Healthcare facilities maintenance management: a literature review. Journal of Facilities Management. https://doi.org/10.1108/jfm-10-2016-0040

Zhao, X. (2017). A scientometric review of global BIM research: Analysis and visualization. Automation in Construction, 80, 37-47. https://doi.org/10.1016/j.autcon.2017.04.002

Zhong, R. Y., Peng, Y., Xue, F., Fang, J., Zou, W., Luo, H., ... Huang, G. Q. (2017). Prefabricated construction enabled by the Internet-of-Things. Automation in Construction, 76, 59-70. https://doi.org/10.1016/j.autcon.2017.01.006

\section{Copyrights}

Copyright for this article is retained by the author(s), with first publication rights granted to the journal.

This is an open-access article distributed under the terms and conditions of the Creative Commons Attribution license (http://creativecommons.org/licenses/by/3.0/). 